
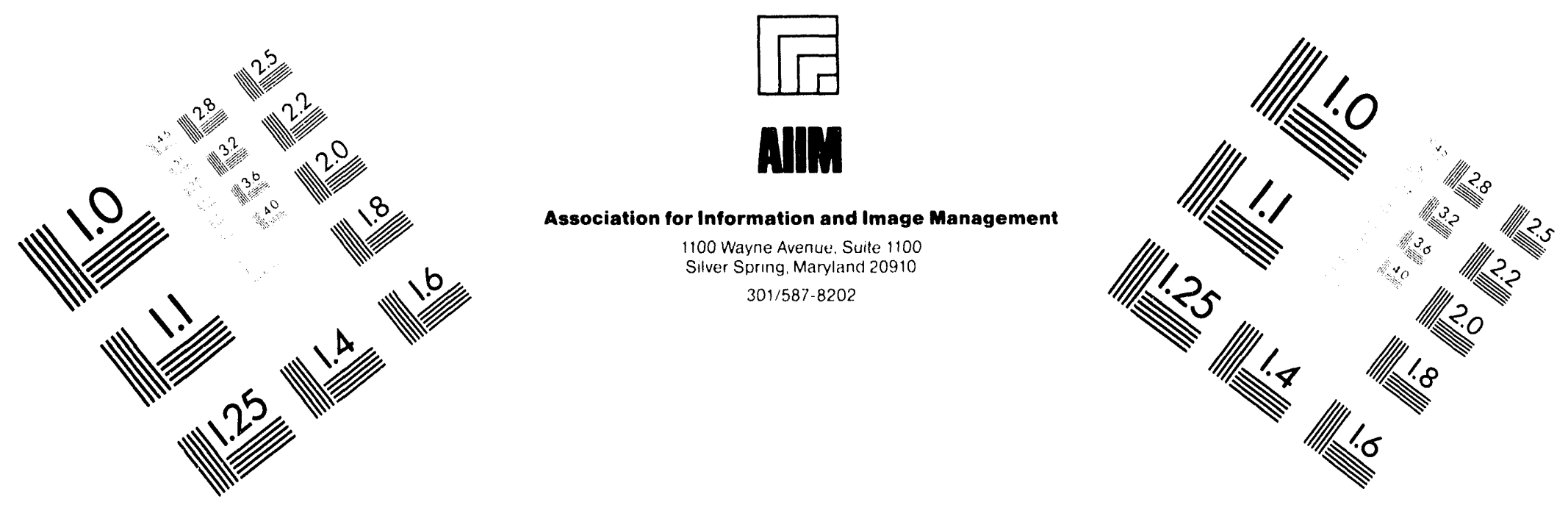

\title{
Centimeter
}

1m

Inches
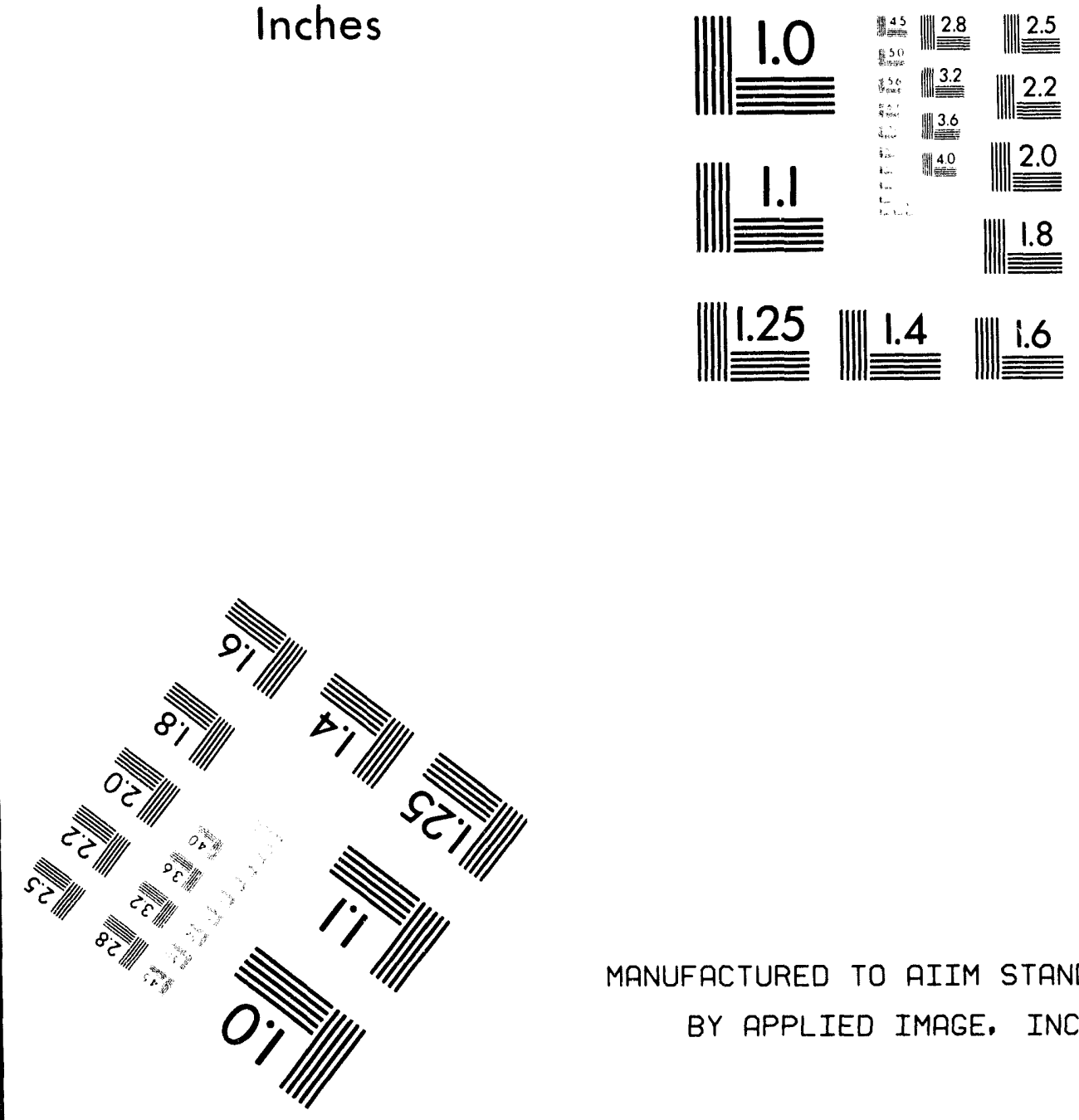

MANUFACTURED TO AIIM STANDARDS

BY APPLIED IMAGE. INC.

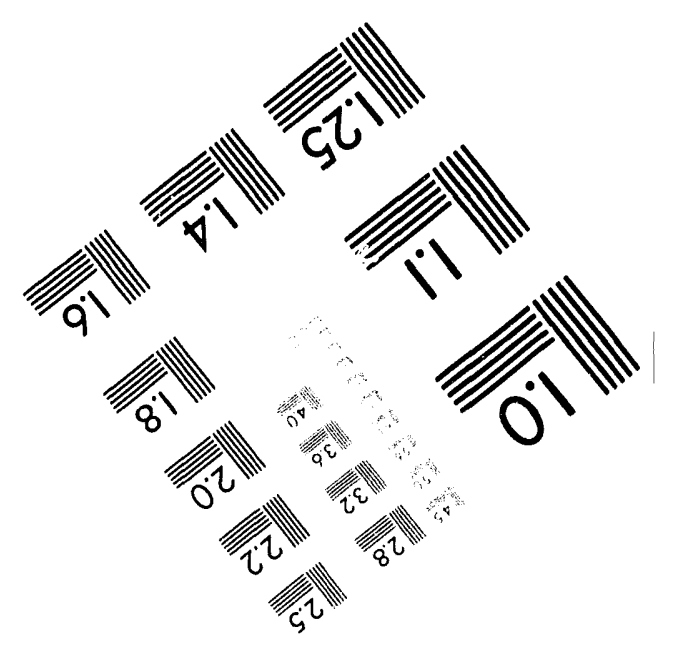



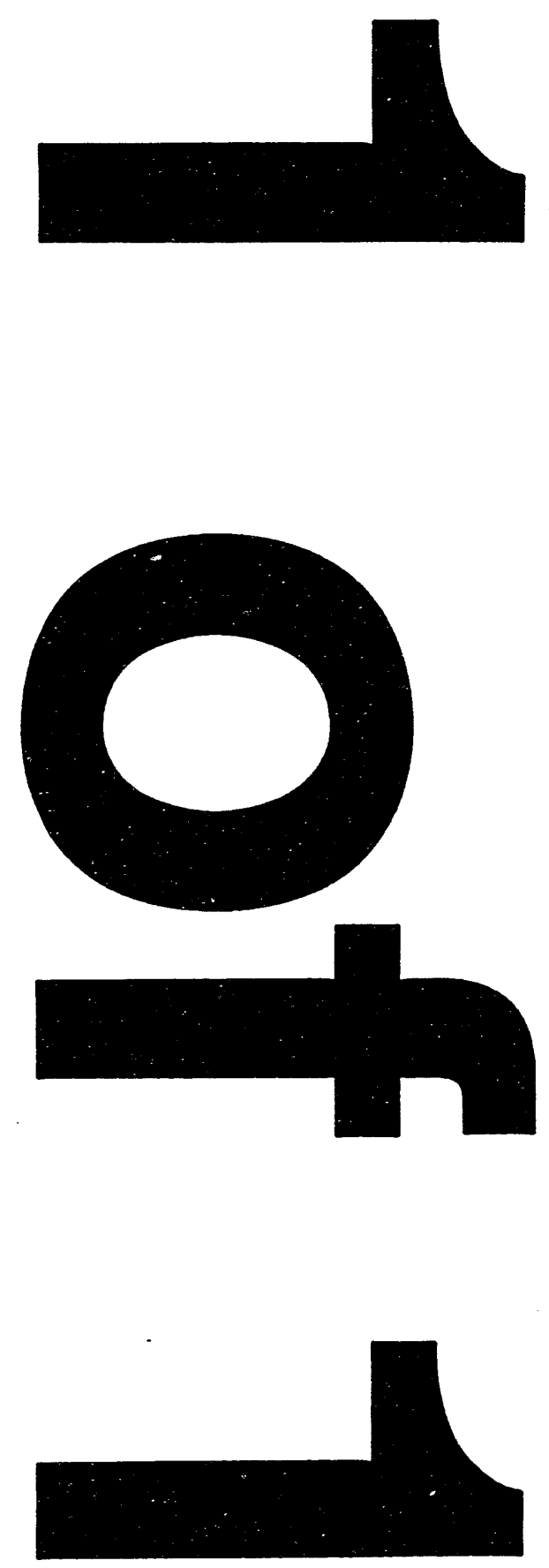
SAND93-3946

Unlimited Release

Distribution Category

Printed April 1994

UC-262

\title{
AN ASSESSMENT OF \\ RESEARCH AND DEVELOPMENT \\ LEADERSHIP IN \\ OCEAN ENERGY TECHNOLOGIES
}

\author{
Vicki L. Bruch \\ Energy Policy and Planning Department \\ Sandia National Laboratories \\ Albuquerque, NM 87185
}

\begin{abstract}
This report provides an assessment of the research and development (R\&D) underway in ocean energy technologies in the following countries: Denmark, France, Germany, Italy, Japan, Russia, and the United Kingdom (UK). Little R\&D is underway due to the poor market potential of these energy technologies. The market potential of ocean energy technologies is low because these technologies are not cost-competitive with conventional sources of energy and their use is quite sitespecific. The UK and Japan have the largest programs in ocean energy technologies. Federallysupported R\&D on ocean energy technologies has stopped in the US. As a result, the US presence in this admittedly small market will probably diminish. Therefore, the US should consider entering into cooperative agreements with Japan and the UK in order to keep abreast of developments in ocean energy technology R\&D. Benefits of cooperative agreements include costsharing and technology transfer.
\end{abstract}

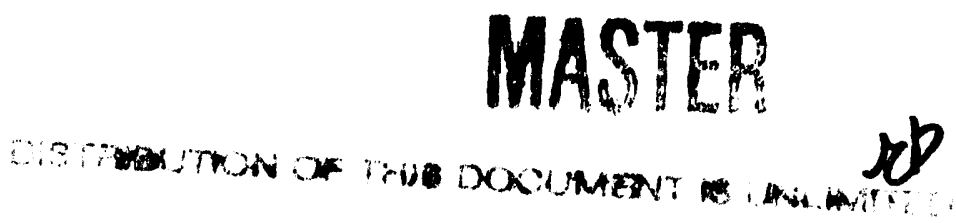




\section{AN ASSESSMENT OF \\ RESEARCH AND DEVELOPMENT \\ LEADERSHIP IN \\ OCEAN ENERGY \\ TECHNOLOGIES1}

\section{EXECUTIVE SUMMARY}

This report presents a review of ocean energy technologies research and development (R\&D) programs underway by selected countries. Ocean energy technologies include:

- tidal energy,

- wave energy,

- ocean thermal energy conversion (OTEC),

- ocean current energy.

Detailed descriptions of these technologies are included in Appendix A.

The market potential for ocean energy technologies is quite low because the technologies are not yet cost-competitive with conventional sources of energy; and, use of these technologies is quite site-specific. It is expected that the initial market for ocean energy technologies will be island nations in the Pacific because they have ocean resources suitable for ocean energy technologies, low energy requirements, and high fossil energy fuel costs.

There is little R\&D underway on ocean energy technologies in the study countries (Denmark, France, Germany, Italy, Japan, Russia, and the United Kingdom). Most R\&D is being performed in the United Kingdom (UK) and Japan. The UK is pursuing ocean energy

\footnotetext{
1 This position paper was prepared as part of a study covering several emerging energy technologies. The study was conducted at the request of the Office of Foreign Intelligence, Office of Intelligence of the Department of Energy. Numerous unclassified intelligence sources and open source documents available as of May 21, 1993, were used. In addition to written materials, interviews with technical experts were conducted. The interviews represented a cross section viewpoint from academia, the national laboratories, government, and industry. The conclusions presented here are those of the author.
} 
technologies because of government policies favoring renewables and suitable ocean resources. While the UK is focusing on tidal power, the high costs and uncertain environmental effects may preclude development of tidal barrages ${ }^{\wedge}$ in the UK.

Japan is focusing its R\&D efforts on wave energy and OTEC. Japan is interested in wave energy because it has adequate wave resources required to generate power. Japan has an active wave energy program and has commercialized small wave energy devices, such as buoys. OTEC (ocean thermal energy conversion) is being investigated by the Japanese primarily for its export potential. OTEC work has included the demonstration of a small plant on the island of Nauru. R\&D work is underway to expand OTEC technology to larger power plants. R\&D ocean energy work in Japan is performed by consortia of universities, private industry, and government.

Both the Japanese and British governments, have supported ocean energy R\&D for several years and both governments are interested in developing export markets for these technologies. Thus, it appears that both countries will remain leaders in the field.

Cooperative agreements with the UK and/or Japan would be beneficial to the United States (US), particularly now that US government funding of all ocean energy R\&D has stopped. The agreements would benefit the US in cost-sharing and technology transfer and would aid in ensuring the US maintains both knowledge and a presence in the world energy market for ocean energy technologies.

Federally-supported R\&D on ocean energy technologies was stopped in the US because the market potential was deemed to be low and the US Department of Energy (DOE) determined that other renewable energy technologies offer more promise than ocean energy. Also, the DOE believes the market for these technologies is overseas and that no domestic market exists for these technologies.

\footnotetext{
$2 \mathrm{~A}$ barrage is an artificial obstruction in the water, essentially a dam with openings to allow ships to transit.
} 


\subsection{MARKET POTENTIAL}

The market potential over the next 10 to 20 years for ocean energy technologies is considered to be low because most of the work on these technologies is in the early stages of development and is not cost-competitive with current energy sources. Estimated electric generating costs of the various ocean energy technologies range from $3-25 \notin$ per kilowatt hour $(\mathrm{kWh})$ depending upon the discount rate. ${ }^{3}$ For island nations with low power needs and oil dependency, the cost of ocean energy, particularly if it falls into the lower range, could be competitive with conventional fuel sources. The high capital costs associated with these technologies preclude these island nations from constructing ocean energy facilities; financial and technical assistance must come from developed nations.

In general, ocean energy technologies require the use of expensive equipment. OTEC in particular requires large turbines and a cold water pipe with a diameter of at least four feet. Tidal energy developments require tremendous capital and land resources. It is estimated that the proposed Severn tidal barrage in the UK, at approximately 8,000 megawatts (MW) will cost more to construct than the Channel Tunnel [1].

Because of the high costs of ocean energy technologies and the low costs of conventional fuels, ocean energy technologies are not expected to be commercially viable until 2010 or 2020. Even then, the use of ocean energy will probably not contribute more than one or two percent of the world's total energy requirements. There is little grid-connected electricity being generated by ocean energy at the present time. Four tidal energy facilities produce approximately 262 MW of power (almost all the energy is produced in one facility in France) [2] and a few small wave energy plants generate less than half a MW of power (one large facility in Norway and several small plants in Japan) [3].

Also hindering the market potential of ocean energy technologies is the fact that these technologies are quite site-specific. Tidal energy can most effectively be used in regions with high tidal ranges. There are only a few regions in the world with this criterion, some of which are remote. Regions where tidal energy would be possible include the UK, France, the

\footnotetext{
3In the US, conventional sources of energy, such as coal, generate electricity at $3-4 \phi / \mathrm{kWh}$. Wind energy, at $5 \notin / \mathrm{kWh}$, is expected to be the first renewable source of energy to significantly penetrate the market.
} 
northeastern coast of North America, the east coast of South America, and certain areas in Asia (India, Korea, and the Kamchatka Peninsula in Russia). The use of OTEC is limited to regions where the temperature difference between the surface water and deep water is at least $20^{\circ} \mathrm{C}$. The needed ocean depth for this temperature difference to occur is approximately 3,000 feet. This limits the use of OTEC to regions found between the Tropics of Cancer and Capricorn. One advantage OTEC has that may help it penetrate the market is its ability to produce fresh potable water. For all ocean energy technologies, it is critical, primarily for costcompetitiveness reasons, that the energy development be located near an existing power grid.

\subsection{OCEAN ENERGY R\&D ACTIVITIES OF STUDY COUNTRIES}

Ocean energy R\&D activities are at a rather low level (due to their low market potential), especially when compared to the $R \& D$ work underway on the other renewable energy technologies, such as wind or solar energy. It is therefore difficult to ascertain who the leader is in the ocean energy technologies. In the context of this report, "leadership" is defined as the country with the greatest number of projects underway and how far the projects have progressed (feasibility study versus demonstration). The amount of R\&D work underway, along with the amount of funding devoted to $R \& D$, provides an indication of the importance a country places on a particular technology.

The leading countries performing R\&D in the past were Japan, the US and the UK. ${ }^{4}$ Japan's efforts were primarily focused on OTEC and wave energy, while the US and the UK have done some work in OTEC, tidal energy, and wave energy. Most of the work was at the development or early demonstration stage -- there are a few small (100 - $500 \mathrm{~kW})$ demonstration plants for the different technologies. The bulk of the ocean energy research underway in the US has stopped with only small privately-funded projects underway.

Government funding for ocean energy technologies R\&D is quite low, in no case exceeding 1.5 percent of any government's total energy R\&D expenditures. (Not all study countries reported funding ocean energy $R \& D$.) Figure 1 presents the amount of government funding

\footnotetext{
4This ranking was compiled by reviewing the projects listed in Compendium of International Ocean Energy Activities, (New York, NY: American Society of Civil Engineers, 1989). Interviews with experts in the ocean energy technology field confirmed this ranking.
} 
spent on ocean energy R\&D for the years 1989 - 1991 for a few of the study countries and the United States.

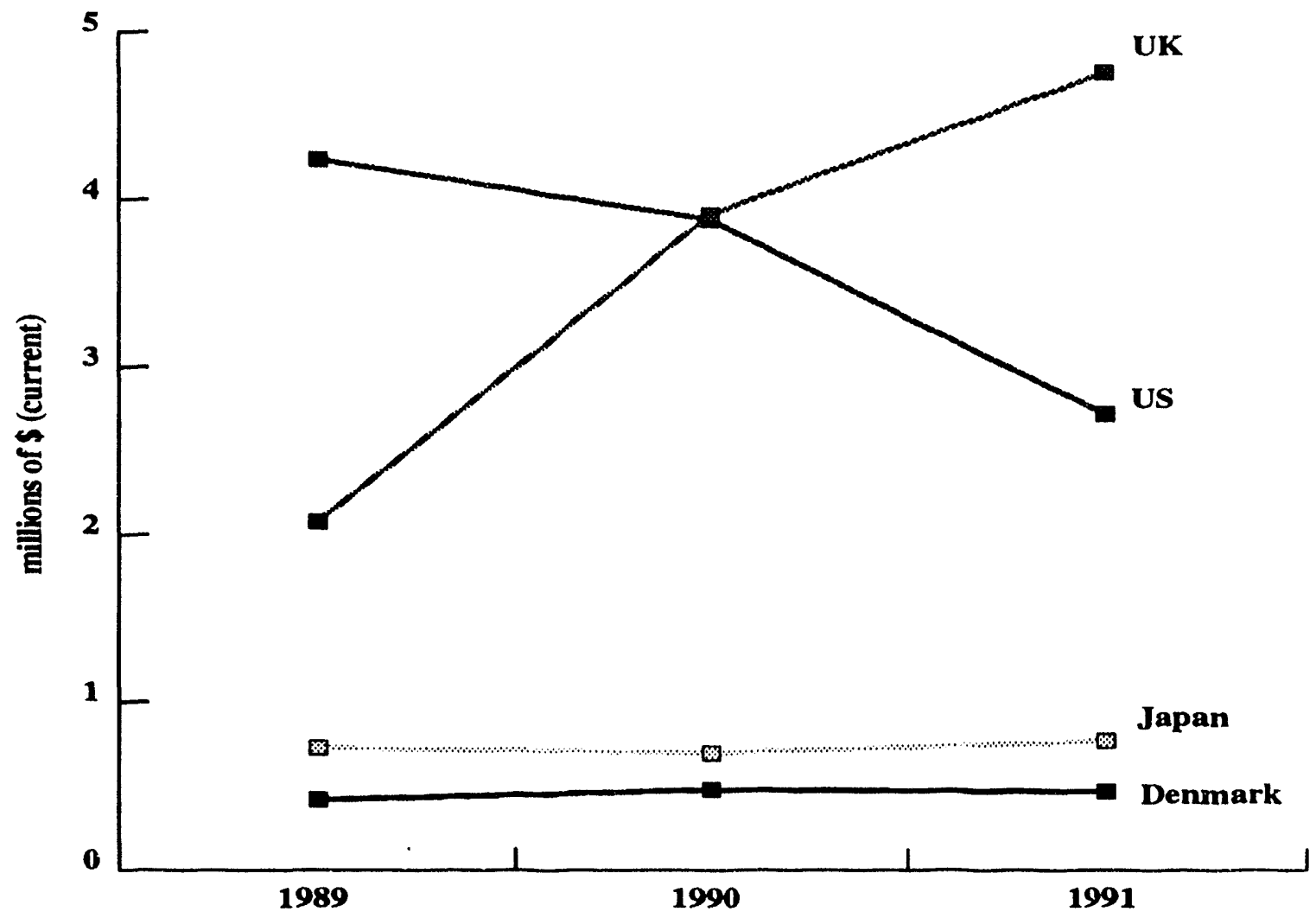

Figure 1. Annual ocean energy R\&D funding for study countries and the United States. Source: International Energy Agency, Paris, France.

It is of some interest to note that during 1989-1991 the UK increased its funding in ocean energy technologies while the other countries were maintaining or decreasing their funding levels. The prime driver for increased funding $\mathrm{r}$ ocean energy technologies in the UK was the Non-Fossil Fuel Obligation.

\subsection{UNITED KINGDOM}

The Non-Fossil Fuel Obligation or NFFO requires the UK's twelve regional electricity companies 5 to derive a certain level of their generating capacity from non-fossil fuel sources

5These twelve regional conipanies were formed when the UK privatized its electricity supply industry. 
[4]. It was originally intended to promote nuclear power but also requires a certain amount of generating capacity be provided by renewable energy. The British government has a target of 1,000 MW of new electrical generating capacity from renewable energy sources by the year 2000 [5]. The total installed electrical generating capacity in the UK is currently $70,000 \mathrm{MW}$ [4].

Ocean energy R\&D in the UK has focused on tidal energy because of the high tidal ranges in the UK. Tidal energy does not require new advanced technological requirements. The technology which would be used to harness tidal energy is quite similar to the technology now used for hydroelectric power. The main objective of the UK government's tidal energy R\&D program is to reduce uncertainty on costs, performance, and regional and environmental issues to the point where it will be possible for private industry to make a decision on whether or not to plan for the construction of tidal barrages [6].

Feasibility studies (jointly funded by the government and private industry) on tidal energy are underway at the following estuaries: Severn, Mersey, Wyre, and Conwy. The Severn is the largest at approximately 8,000 MW. 6 A Severn tidal energy plant could meet approximately six percent of the electricity requirements of England and Wales [7]. The proposed sizes of the other three tidal barrages are $700 \mathrm{MW}, 47 \mathrm{MW}$, and $33 \mathrm{MW}$, respectively.

R\&D work on tidal energy in the UK has not progressed past the feasibility study stage because it is unclear if tidal energy can be cost competitive with conventional energy sources. As noted earlier, tidal energy schemes have high capital costs and can involve lengthy construction times (seven to ten years). Capital costs for the largest tidal energy project, the Severn Barrage, are estimated at $\$ 1,800 / \mathrm{kW}$ with electric generating costs around $8 \notin / \mathrm{kWh}$, at a six percent discount rate, compared to $3 \notin / \mathrm{kWh}$ for coal-fired power plants [2]. Because of the high capital costs and financial risks, the likelihood of private industry funding for tidal barrages is questionable.

Another reason that tidal energy has not passed the feasibility study stage in the UK is the uncertainty and concern regarding the environmental effects of harnessing tidal energy. Positive environmental effects of tidal energy include no greenhouse gas emissions, no

${ }^{6} \mathrm{At} 8,000 \mathrm{MW}$, the Severn tidal barrage is the largest renewable project in the UK. 
emissions that could cause acid rain, and no waste disposal problems. However, less is known about the possible negative environmental impacts. Two chief concerns are the possible impact on bird populations and the fish mortality rate as the fish pass through the turbines. All the major estuaries studied for tidal power in the UK are of international importance for wintering wildfowl [1]. There is concern the tidal barrages would cause a loss of habitat and disrupt the feeding patterns of birds. Because of the possible negative environmental impacts, most environmental groups in the UK are opposed to tidal energy development.

Besides tidal energy, the other form of ocean energy that has generated interest in the UK is wave energy. Wave energy R\&D began in the UK in 1974, and for many years was the largest wave energy program in the world. Over 300 wave energy concepts were examined. In 1982, the wave energy program was severely curtailed because the economic prospects for large-scale offshore wave energy did not look promising in comparison with other technologies, such as wind energy [3].

Wave energy R\&D in the UK is now at a substantially lower level than it was in the past. Two government advisory panel recently (1993) recommended wave energy $R \& D$ receive no further government R\&D money due to poor economic prospects; electricity could be produced for approximately $9 \notin / \mathrm{kWh}[8]$. Wave energy work currently underway in the UK is focused on three devices. One device, an oscillating water column developed by the Queen's University in Belfast, is undergoing trial operation off the coast of Scotland.

R\&D work in the other forms of ocean energy (OTEC and ocean current energy) is minor compared to the R\&D work underway in tidal and wave energy. The UK is interested in developing OTEC primarily because of its export potential. The ocean waters surrounding Great Britain do not have the high temperature differences required for OTEC. Two British OTEC programs are underway in Hawaii at the Natural Energy Laboratory. The Department of Trade and Industry, Ocean Thermal Energy Conversion Systems (a private firm), and the Universities of Newcastle and Manchester are developing a $10 \mathrm{MW}$ floating OTEC plant. The second project is a $500 \mathrm{~kW}$ land-based OTEC plant being developed by private industry, GEC-Marconi Research and Alcan (a Canadian firm). 
Only one ocean current energy project is underway in the UK. The consortium of Scottish Nuclear, IT Power, and the National Engineering Laboratory plan to construct and test a 10 $\mathrm{kW}$ wind-type turbine anchored to the seabed. The ocean current will turn the turbine, generating electricity. A British government study released in 1993 reported several negative factors of this ocean current energy project, including serious maintenance problems [9].

The R\&D work underway in the UK is indicative of the status of ocean energy research in other countries-many studies but little actual development and demonstration of the technologies. The UK government appears to be focusing its effort on tidal energy. However, due to the high costs and the possible negative environmental impacts of tidal energy, it is questionable whether the proposed tidal barrages will ever be built in the UK.

\subsection{JAPAN}

Like the United Kingdom, Japan has performed many studies on ocean energy technologies. Unlike the UK, Japan has progressed to demonstrating several devices, particularly for wave energy.

The Japanese have concentrated on wave energy and OTEC. Japan has good resources in the Sea of Japan for wave energy. Ocean conditions around Japan have high amounts of potential energy created by winds blowing across the ocean. The Japanese are primarily interested in the export potential of OTEC as the country has no suitable resources of its own for OTEC. Japan has had an active wave energy R\&D program for 30 years. The Japan Marine Science and Technology Center, began investigating offshore devices for wave energy in 1974. Its work has focused on the Kaimei, a floating ship that tested different pneumatic devices. The Kaimei is considered one of the more advanced large (approximately $125 \mathrm{~kW}$ ) wave energy devices. Development of the Kaimei was an International Energy Agency project funded by the US, Canada, the UK and Ireland. 
The first commercial wave energy product, a navigation buoy, was developed by the Japanese in 1964-65. Navigation buoys powered by wave energy have been installed in various sites around the world. 7 Approximately 1,200 buoys have been sold.

R\&D work in wave energy in Japan is performed by government/industry consortia. Members of the different consortia are identified for three demonstration projects currently underway[3]:

- A $20 \mathrm{~kW}$ caisson-based "Pendulor System" at Mashike Harbor, located on the west coast of Hokkaido, operating since 1983. Developed by the Muroran Institute of Technology and Hitachi Zosen Corporation.

- A $30 \mathrm{~kW}$ single-acting oscillating water column at Kujukuri, on Honshu's east coast, operating since March 1988. Developed by Takenaka Corporation and Kawasaki Steel Corporation.

- A $60 \mathrm{~kW}$ caisson-based, double-acting oscillating water column at Sakata Port, on the Sea of Japan, operating since November 1989. Developed by the Ministry of Transport's Port and Harbor Research Institute.

Like wave energy R\&D, OTEC R\&D is performed by government/industry consortia. Japanese R\&D work in OTEC began in 1970 by the Tokyo Electric Power Services Company. It has developed and demonstrated a successful $100 \mathrm{~kW}$ closed-cycle OTEC plant for the island of Nauru and is designing a $10 \mathrm{MW}$ floating closed-cycle OTEC plant for use on this island. The Ministry of International Trade and Industry is supporting this work. The Japanese government is also supporting work on the design of a $1 \mathrm{MW}$ floating closed-cycle OTEC plant. Other institutions engaged in OTEC R\&D include Kyushu Electric Power Company and the University of Saga.

Ocean energy R\&D in Japan has benefitted from consistent government support, although the support has been at a low level. This has allowed Japanese industry to advance from the research and development stage to the demonstration stage for several ocean energy devices. This has given the Japanese a "leg up" on their competition, and as a result, Japanese ocean

7 The US Coast Guard investigated using wave-powered buoys but chose to use buoys powered by photovoltaics due to the varying ocean conditions in the US. 
energy technologies will probably be commercialized sooner than ocean energy technologies from other countries.

\subsection{OTHER STUDY COUNTRIES}

Little work in ocean energy R\&D is underway in the remaining study countries, primarily due to lack of government support and poor market potential for the technologies. No information was found on government-supported ocean energy R\&D in Germany or on projects sponsored by the European Union (formerly known as the European Community).

The only ocean energy work underway in France and Russia concerns tidal energy. France has the world's largest tidal power facility at $240 \mathrm{MW}$. This plant has been operating since 1966 and has a good operating record. It now generates electricity at approximately $1.5 \& / \mathrm{kWh}$. France was pursuing a $5 \mathrm{MW}$ OTEC plant for Tahiti, but that work has stopped primarily because of lack of funding. Russia has a small $400 \mathrm{~kW}$ tidal plant that has operated since 1968. Feasibility studies for tidal energy development at other sites in Russia are underway. No additional information was found regarding other ocean energy R\&D projects in Russia.

Denmark has had a small program investigating wave energy since 1979. Almost all of the funding has been provided by the Danish government with the actual R\&D work performed by Danish Wave Power, a consortium of four private companies. The Danes have concentrated on development of a seabed-mounted hydraulic pump and electrical generator driven by a floating buoy.

Italy's sole ocear energy project is to exploit the ocean current energy in the Strait of Messina. A group of Italian and German companies (Saipem, Technomare, Ponte di Archimede, and Voith) plan to erect 100 wind-type turbines on the sea floor. The Italians believe the energy produced would be cost-competitive with energy produced by conventional fuels. Constructing the pilot ocean current plant would cost approximately $\$ 31.5$ million. The Italians hope the funding will come from the European Union [10]. 


\subsection{EXPLOITING THE R\&D POTENTIAL OF OTHER COUNTRIES}

Research and development work in the study countries could potentially be of benefit to US researchers. Only two study countries, the UK and Japan, are performing R\&D that would benefit US R\&D efforts. One tool that could be used to exploit the ocean energy R\&D potential of these two countries is a cooperative agreement between the US and another country. The benefits of a cooperative agreement include both cost-sharing and information-sharing. The cooperative agreement would also ensure that the US maintains a presence in the ocean energy technology market, even though the market for these technologies does not appear large. Cooperative agreements can aid in passing new technologies jointly developed by US and foreign researchers to US industry. This is particularly crucial now that the US government is no longer sponsoring ocean energy R\&D.

Cooperative agreements could prove to be beneficial to the US. One benefit would include cost-sharing. Ocean energy technologies tend to be quite expensive to develop and demonstrate. Sharing these costs with another country would help ensure that the US remains active in ocean energy R\&D without causing major strains on the federal budget.

Another benefit of a cooperative agreement with either Japan or the UK would be to allow the US to tap into the expertise of the researchers in that country. Some of the ocean energy technologies being developed overseas could have important applications in other industries, such as construction and offshore drilling for oil and natural gas (in particular, the technology used to develop long pipelines needed for ocean energy could be applicable to the oil and gas industry). Cooperative agreements will aid US industry in maintaining a market presence both in existing markets (offshore oil drilling) and new markets (ocean energy).

\subsection{IMPLICATIONS FOR THE UNITED STATES}

In the past, the US devoted substantial sums of federal funding to ocean energy R\&D. The bulk of the funding was devoted to OTEC. However, US funding has dropped precipitously over the years as shown in Figure 2. 


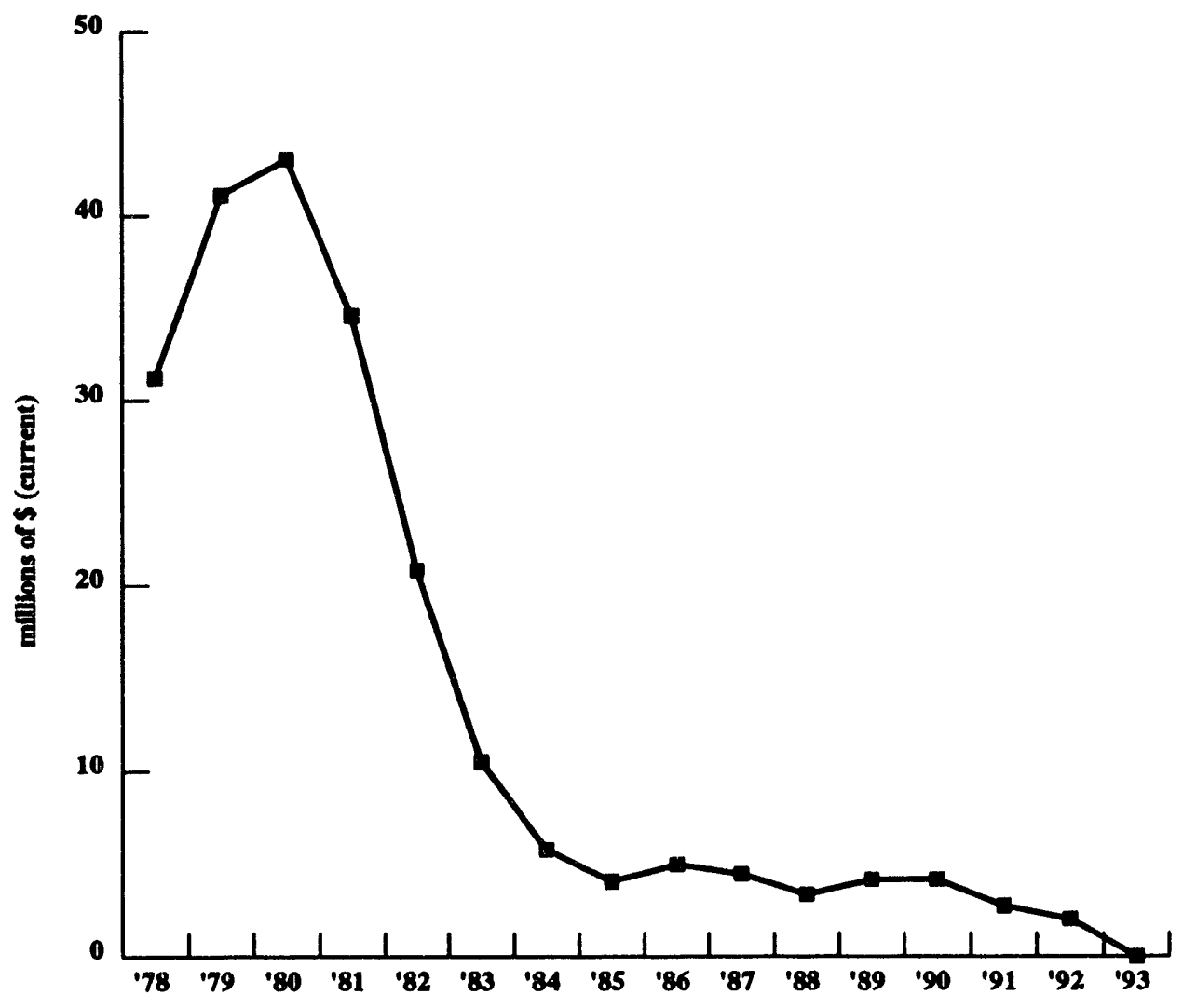

Figure 2. US DOE ocean energy funding. Source: Fred J. Sissine, Renewable Energy: A New National Commitment? Congressional Research Service Issues Brief, January 6, 1992.

Ocean energy R\&D funding has undergone severe cutbacks, primarily due to the change in energy R\&D philosophy from the Carter Administration to the Reagan and Bush Administrations. However, the situation is not expected to improve under the Clinton Administration because of the belief that other renewable sources of energy will have a greater impact on the energy market than ocean energy technologies.

Another reason federally-supported ocean energy R\&D has stopped in the US is the belief that there is no domestic market for these technologies. In spite of the fact that an export market does appear to exist, albeit of unknown size, there appears to be little US government interest in exploring its possiblities.8 This point of view is the opposite of the Japanese government.

8Lloyd Lewis, Program Manager, Wind/Ocean/Hydro Program, US Department of Energy. Personal interview with Vicki Bruch, May 13, 1993. 
The Japanese government is quite interested in export markets for their technologies and will often undertake R\&D of a particular technology strictly for its export potential.

The US government stance could well prove to be short sighted in the long term. Although the market potential for ocean energy technologies appears to be small, that could change in the future, particularly if the world converts to hydrogen-based fuels. Ocean energy technologies could be quite important in the future in terms of exploiting hydrogen from the ocean. This hydrogen could then be used in other energy technologies such as fuel cells. Foreign competitors could potentially leap ahead of US industry in cieveloping and marketing ocean energy technologies due to US government policy.

The intense R\&D efforts in the 1970s allowed the US to make great strides in developing ocean technologies, particularly in OTEC. The US was the first to design, develop, and demonstrate an open-cycle OTEC plant. Lack of federal government funding and the lack of interest expressed by the US government has set back US efforts in ocean energy R\&D. The State of Hawaii is continuing to investigate OTEC, although on a much smaller scale compared to past efforts. Much of the ocean energy work now underway in Hawaii is being done by Japan and the UK-Canada consortium.

One bright spot for the US in ocean energy R\&D is the possible entrance of defense contractors into the field. These companies are interested in pursuing ocean energy technologies because of declining defense work and the belief that ocean energy R\&D matches well with past work, such as submarine design. Defense companies generally have a well-educated workforce with large financial and physical resources. Several US defense companies were involved in ocean energy R\&D in the 1970s.9

\subsection{CONCLUSIONS}

Japan is clearly the leader in ocean energy technologies. The United Kingdom also has had many ocean energy research projects, but unlike Japan, most of the British projects have not progressed from the feasibility study stage to the demonstration stage. Federally funded ocean

9Lloyd Lewis, Program Manager, Wind/Ocean/Hydro Program, US Department of Energy. Personal interview with Vicki Bruch, May 13, 1993. 
energy research in the US was stopped because it was perceived the technologies could not compete with conventional sources of fuel.

Despite the probable small market for ocean energy technologies, the short sighted viewpoint of the US government regarding funding of these technologies may be harmful to US economic competitiveness. The technologies may have important uses in other applications, such as offshore construction and oil and gas drilling. Discontinuing the research and development of these technologies may cause the US to lose knowledge and miss market opportunities.

If the US wishes to maintain its knowledge base and a market presence for ocean energy technologies, it may wish to consider entering into a cooperative agreement with Japan and/or the United Kingdom. Cooperative agreements are beneficial not only for technology transfer but also for cost-sharing.

\subsection{INTERVIEWS CONDUCTED}

The following individuals were interviewed regarding issues of international technological competitiveness and markets. Additional interviews of Russian scientists and experts familiar with the Russian economic and political situation were conducted for the author by the Foreign Systems Research Center (FSRC) of Science Applications International Corporation (SAIC). Finally, the US/Japan Center at the University of New Mexico conducted interviews for the author of numerous contacts in the Japanese R\&D infrastructure and Japanese industry.

John Flynn

Jim Green

George Hagerman
Program Manager, Hydro Program, US Department of Energy

Senior Engineer, National Renewable Energy Laboratory

President,

SEASUN Power Systems 
Lloyd Lewis

Glenn Lovin

Richard Seymour

Patrick Takahashi

Andrew Trenka

Joe Van Ryzin
Program Manager, Wind/Ocean/Hydro Program, US Department of Energy

Senior Engineer,

DynCorp--Meridian

Director, Offshore Technology Center

Texas A\&M University

Director,

Hawaii Natural Energy Institute

Vice President of Operations,

Pacific International Center for High Technology

Research

President,

Makai Ocean Engineering 


\section{REFERENCES}

1. Milne, Roger, “Tidal Power Ruffles Feathers," New Scientist, May 26, 1988.

2. Cavanagh, James E., et al., "Ocean Energy Systems," Renewable Energy Sources for Fuels and Electricity, eds. Thomas B. Johansson, et al., Washington, DC, Island Press, 1993.

3. Hagerman, George, "Wave Energy," 1992 Survey of Energy Resources, World Energy Conference.

4. Hague, Barry, "Realising the Renewable Dream," Atom, January 1991.

5. American Embassy, "UK Environmental White Paper 'This Common Inheritance,' Second Year Report-Domestic Aspects," cable, London, England, November 16, 1992.

6. Morrison, Peter, "Opening Address," Developments in Tidal Energy, London, Thomas Telford, 1990.

7. "Fishing for Power," Engineering, October 1990.

8. American Embassy, "Troubled Waters for UK Wave Energy Research," cable, Loridon, England, January 5, 1993.

9. American Embassy, "More Problems for UK Wave Energy Research," cable, London, England, April 26, 1993.

10. Foreign Broadcast Information Service, Take 14 of 21-S\&T Perspectives-Vol. 8 No. 5 30 Apr 93, cable, Reston, VA, April 28, 1993. 


\section{Appendix A}

\section{Technology Description}

There are four principal methods to capturing energy from the ocean:

- tidal energy,

- wave energy,

- ocean thermal energy conversion (OTEC),

- ocean current energy.

More exotic methods of extracting energy from ocean resources include marine biomass and salinity gradients. However, little research and development is underway in these areas. This appendix will focus on the four primary methods of capturing ocean energy.

The use of ocean energy technologies has many benefits. These benefits include minimal environmental impacts compared to fossil fuel energy, no fuel costs, and enhanced energy security for the nations that use these technologies. Several nations, particularly South Pacific island nations, are especially interested in utilizing ocean energy technologies because of these benefits. However, there are disadvantages to using ocean energy technologies. These disadvantages will be discussed in the individual technology sections.

\section{TIDAL ENERGY}

The extraction of energy from ocean tides is based upon capturing a large amount of water at high tide behind an artificial barrier, such as a barrage, and releasing it through a turbine generator system a few hours later when the ocean's level has dropped towards low tide[1]. The technology for tidal power is proven. A diagram of the proposed Severn barrage in the UK is shown on the next page. 


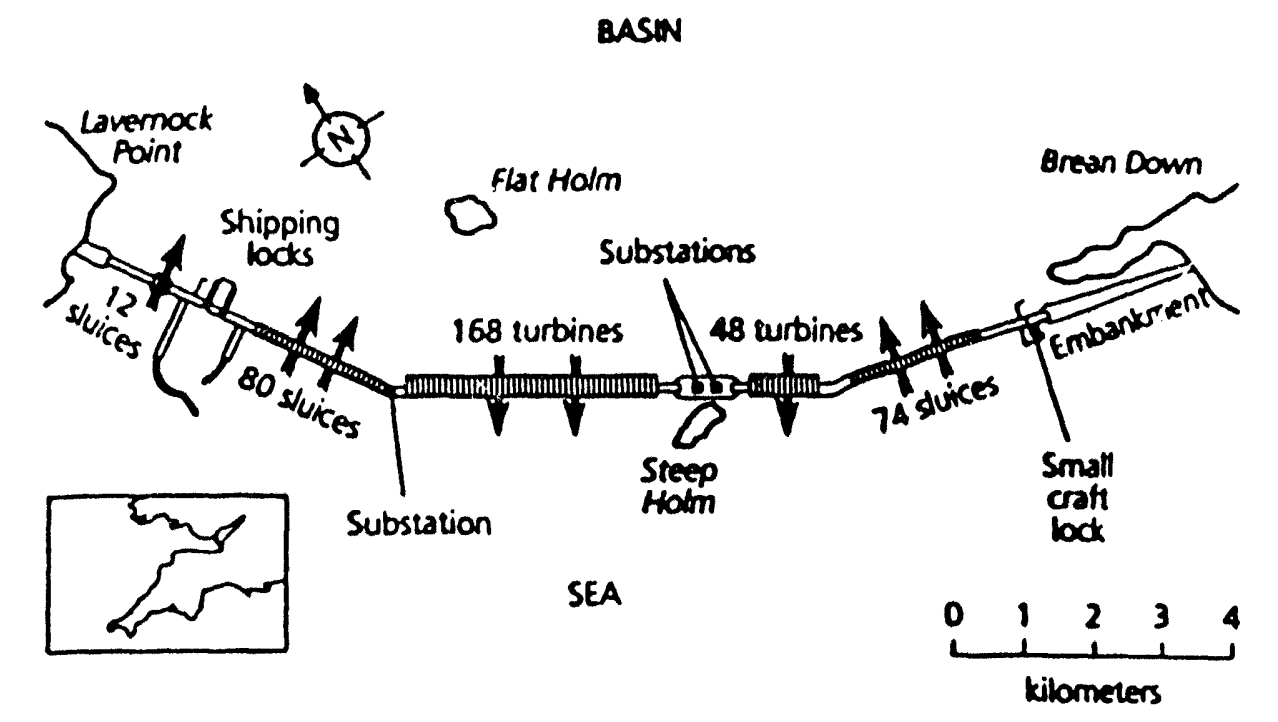

Figure A1. Schematic representation of the proposed Severn tidal barrage in the UK.

Source: James E. Cavanagh, et al., "Ocean Energy Systems" in Renewable Energy Sources for Fuels and Electricity, ed. Thomas B. Johansson, et al, (Washington, D.C.: Island Press, 1993), 519.

The construction of the barrage and the required capital items identified in the diagram are the principal costs of tidal energy. Operating and maintenance costs are relatively low. These high capital costs along with the uncertain environmental impacts are the main drawbacks to developing tidal energy.

\section{WAVE ENERGY}

Wave energy devices convert the vertical component of the wave motion to either mechanical or pneumatic energy, which is then converted to electrical power [1]. There are a variety of wave energy devices as shown in Figure A2. 


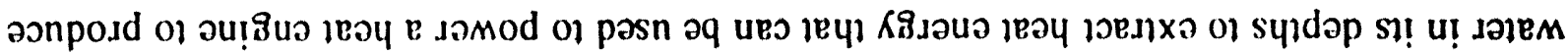

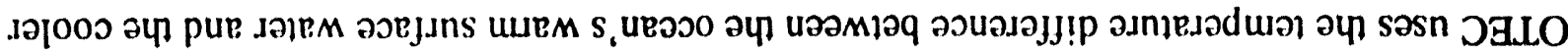

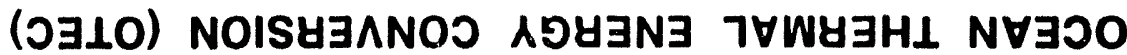

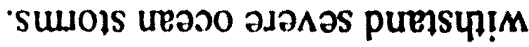

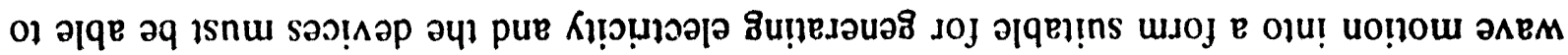

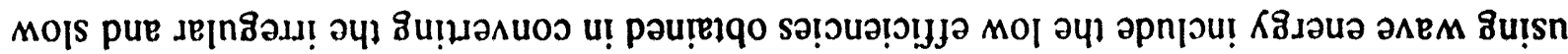

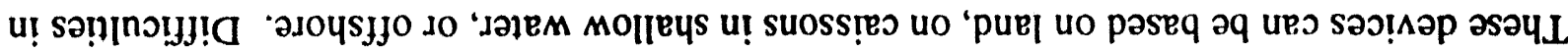

sasınosay 1812ug

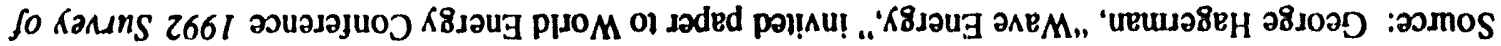

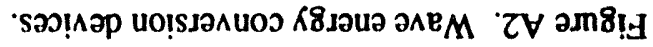

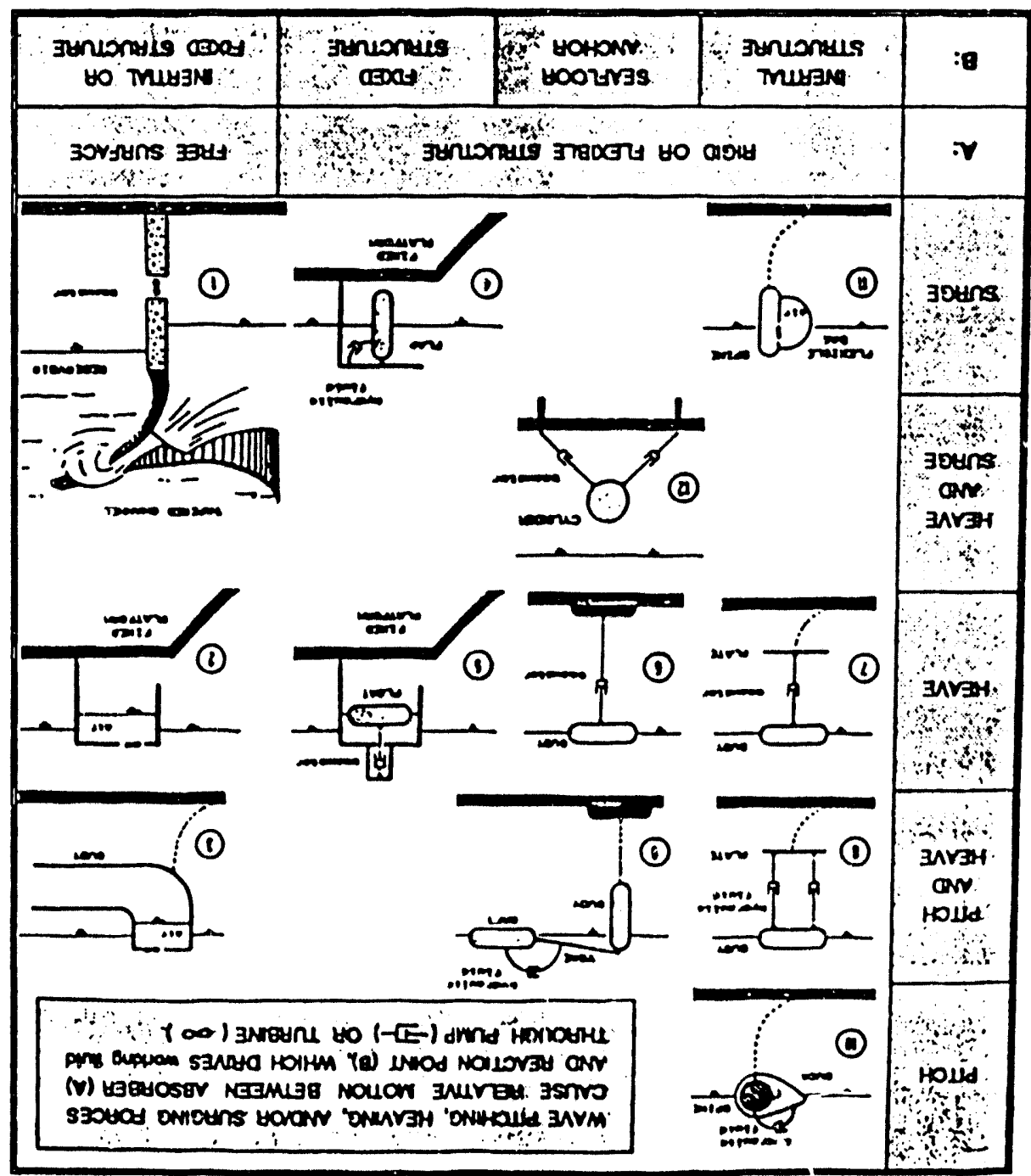


electricity [2]. There are two basic systems: open-cycle and closed-cycle. A hybrid-cycle OTEC plant has elements of both open- and closed-cycle systems.

In an open-cycle system, warm water from near the surface of the sea is pumped into a flash evaporator in which the pressure has been lowered to the point where the warm sea water boils at ambient temperature. This process produces steam that drives a low-pressure turbine to generate electricity. After leaving the turbine, the steam is condensed in a heat exchanger cooled by cold, deep ocean water and produces desalinated water[3]. A diagram of an open-cycle OTEC system is shown in Figure A3.

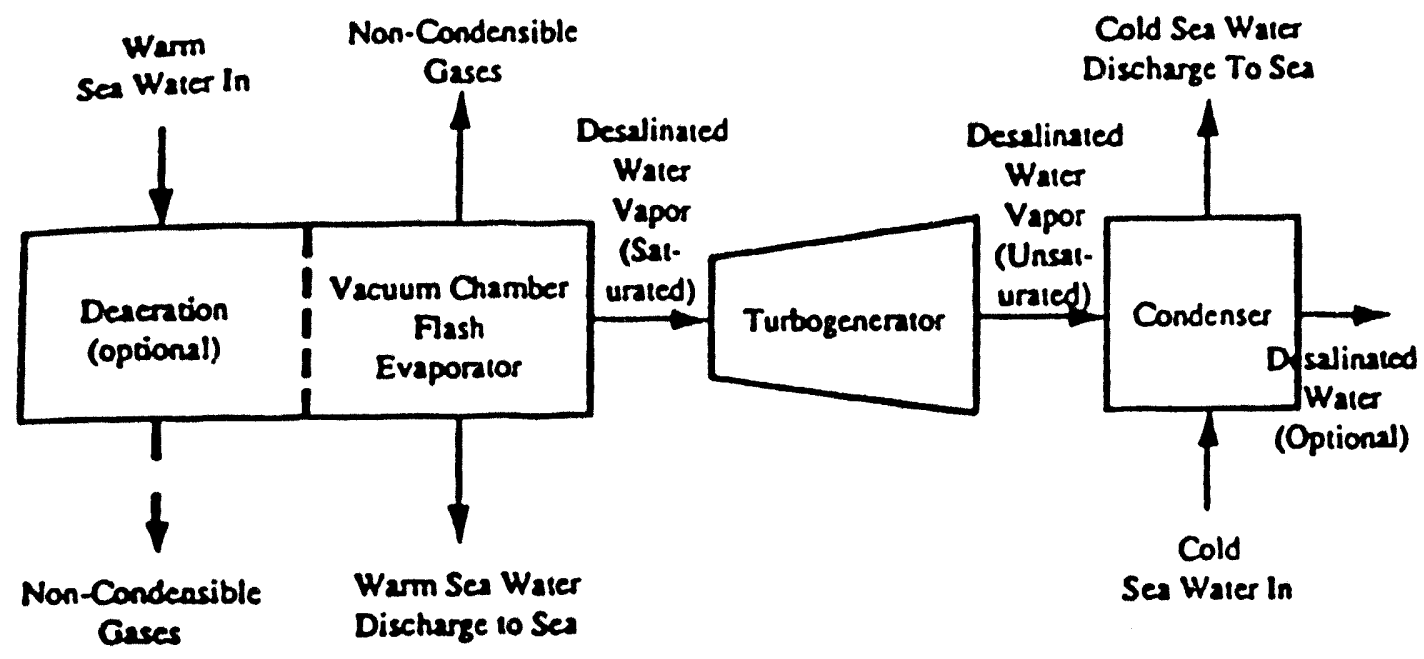

Figure A3. Schematic of an open-cycle OTEC system.

Source: Patrick K. Takahashi and Andrew Trenka, "Ocean Thermal Energy Conversion: Its Promise as a Total Resource System," in Energy, Vol. 17, No. 7, (London: Pergamon Press Lid., 1992), 659.

In a closed-cycle OTEC system, a working fluid with a low boiling temperature, such as ammonia or freon, is used. The fluid is heated and vaporized in a heat exchanger by the warm surface sea water. The steam produced drives a turbine generator. After passing through the turbine, the working fluid vapor is condensed in another heat exchanger cooled by water drawn from the deep ocean. The working fluid is then pumped back through the warm water heat exchanger and the cycle is repeated continuously [3]. A closed-cycle OTEC scheme is shown below. 


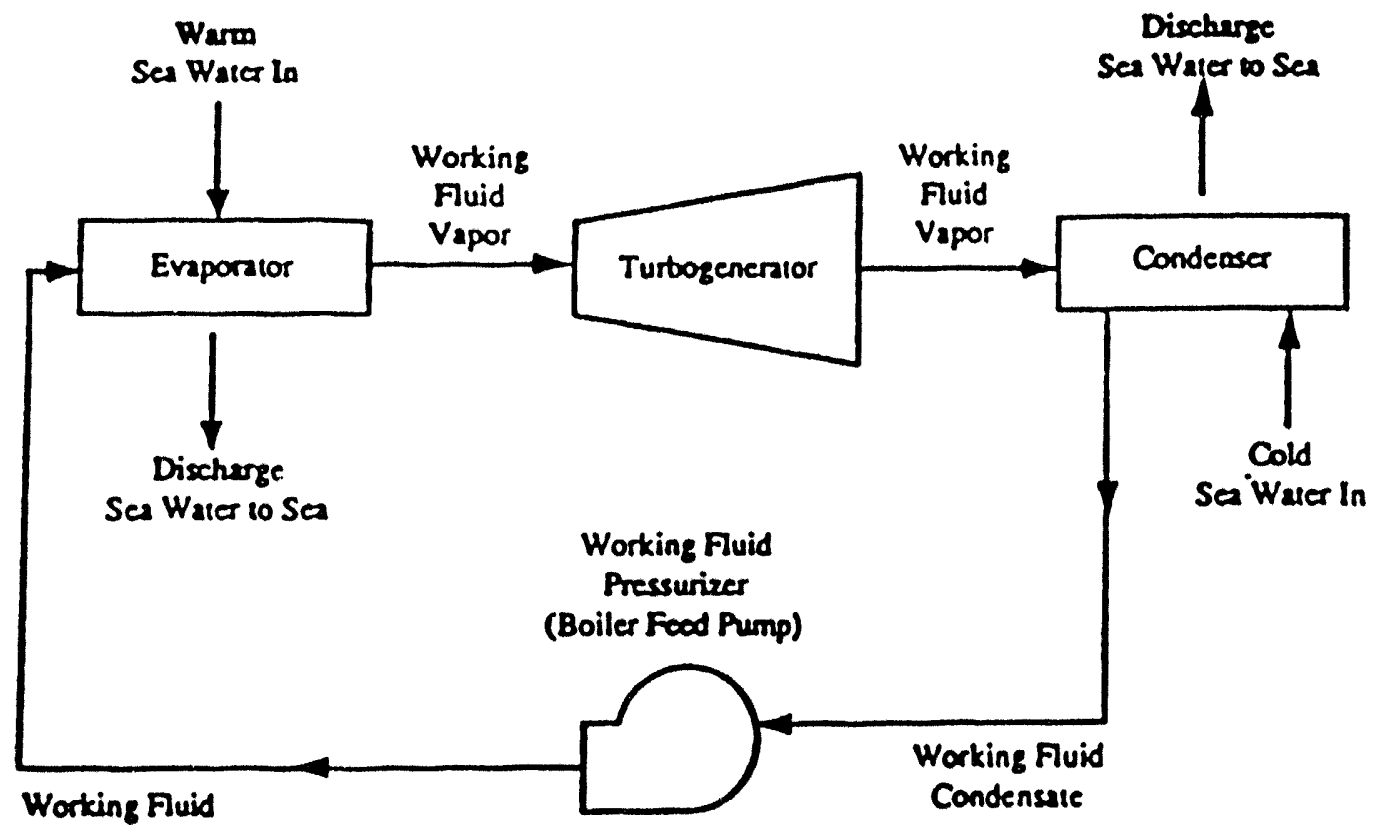

Figure A4. Schematic of a closed-cycle OTEC system.

Source: Patrick K. Takahashi and Andrew Trenka, "Ocean Thermal Energy Conversion: Its Promise as a Total Resource System," in Energy, Vol. 17, No. 7, (London: Pergamon Press Lid., 1992), 658.

The temperature difference between the surface and deep waters is generally small, approximately $20^{\circ} \mathrm{C}$. This low temperature difference requires the OTEC plant to have large equipment needs, driving up the capital cost. However, OTEC systems can be used for other purposes besides power production. OTEC systems can be used in agriculture, air conditioning and refrigeration, and can produce fresh water.

\section{OCEAN CURRENT ENERGY}

Ocean currents that run in and out of coves and bays, supplying and withdrawing large volumes of water, can be used to produce electricity. One way to tap this energy source is to install "windmills" underwater. The turbine can be anchored to the ocean floor or float in the current. Power in ocean currents is typically 10 times more concentrated than in wind [4] and tides are far more predictable than winds. The technology for ocean "windmills" is not as advanced as that of windmills used on land. Little research and development has occurred in ocean current energy. Harnessing current energy may interfere with ship traffic. 


\section{REFERENCES}

1. Fluor Daniel Inc., "Ocean Energy Technologies," Emerging Energy Technology Leadership Study, Volume II: Study Report, Irvine, CA, August 3, 1990.

2. US Department of Energy, "Renewable Energy: An Overview," Information Brochure FS 175, Washington, DC, March 1990.

3. Takahashi, Patrick K. and Andrew Trenka, "Ocean Thermal Energy Conversion: Its Promise as a Total Resource System," Energy, Vol. 17, No. 7, London, Pergamon Press Ltd., 1992.

4. Fay, James A., "Harnessing the Tides," Technology Review, July 1983. 


\section{Distribution}

MS 0722 Vicki Bruch, 6912 (10)

MS9018 Central Technical Files, 8523-2

MS 0899 Technical Library, 7141 (5)

MS 0619 Technical Publications, 7151

MS 0100 Document Processing DOE/OSTI, 7613-2 (10) 

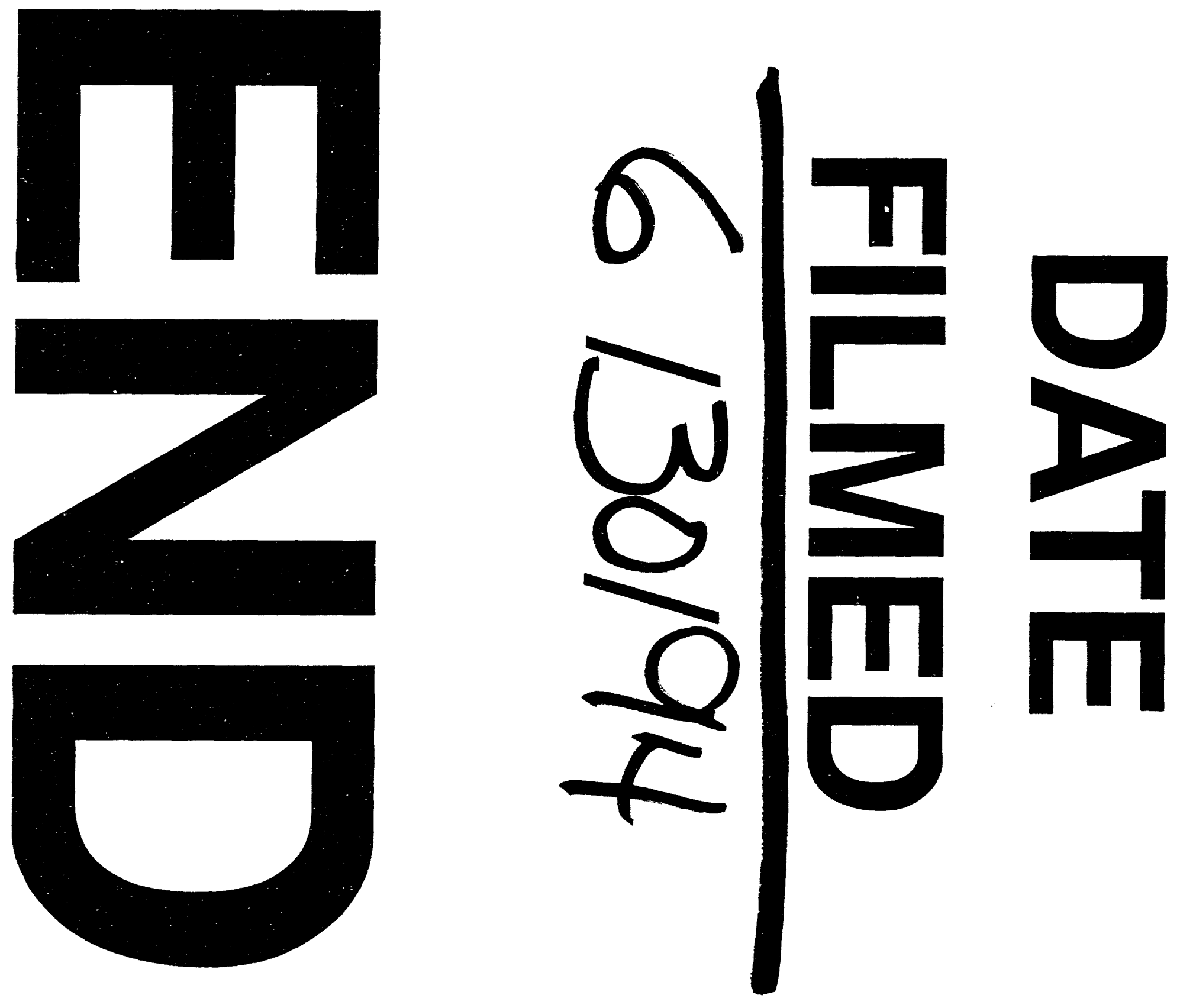